\title{
The Chinese View of Wildlife
}

\section{Susan Shen, Ernest D. Ables and Xiao Qian-zhu}

China is 'conservation conscious' in its attitude towards wildlife, for economic reasons, and is far ahead of most other countries in the rational use of wildlife. Many species, including tigers and black bears, are used for traditional medicines, and many for food. In the densely populated areas little wildlife is left, but the country is so vast, occupying one-seventh of the world's land surface, and has such a variety of habitats, including some very forbidding ones, that much survives. The authors, who visited north-east China in the summer of 1980 , assess what is known and what they saw, and look at some of the problems the Government faces in its conservation programme.

China has a tremendous range of environments, from harsh deserts to lush tropical forests and from sea level to one of the highest plateaux on earth. Wildlife is correspondingly varied, including species with circumpolar distribution and unique forms with very limited ranges. The densely populated regions have almost no wildlife, but other areas support substantial populations. People value wild animals for cultural and aesthetic reasons, but in general their attitude is utilitarian, very much like that of western cultures. The Government has incorporated wildlife conservation into its long-range development plans largely for economic reasons, but the conflicts of interest between exploitation and preservation pose threats for the future. Other problems include a lack of biological information on which to base conservation efforts and a shortage of educated and trained wildlife scientists.

In recent years, the People's Republic of China has taken great strides in conserving renewable natural resources. Even before China's official 're-opening', the few observers who visited the country reported a growing environmental consciousness. In 1975 Westoby predicted that China might become the most forest-conscious nation in the world, ${ }^{10}$ and Myers felt that there was an unprecedented concern for wildlife. ${ }^{6}$ Indeed, this conservation ethic is reflected in government policies and actions; a Green Great Wall campaign has been under way for the last two decades to reforest China's northern border, retard desertification, and reclaim valuable land. ${ }^{10}$ Parcels of protected areas have been established since 1960, with four aims: conservation, production, research, and tourism. ${ }^{9}$ In 1979 , a new Forestry Act was ratified that emphasized production and protection of forest resources, ${ }^{3}$ and later that year, the first comprehensive Environmental Protection Law was proclaimed, and China agreed to join the International Union for Conservation of Nature (IUCN) and adhere to the CITES Convention. ${ }^{7}$ Moreover, in September 1980, a new Wildlife Policy Act was formulated stressing rational use and conservation of wildlife.

At the same time, China has embarked on a very ambitious economic development plan to industrialize the country. Its goals are to reduce the annual population growth rate and quadruple per capita GNP to US $\$ 1000$ by the year $2000,{ }^{11}$ but not at the expense of the environment. China recognizes that the combination of industrialization and a population numbering nearly one billion will exert great pressures on the environment and natural resources, and the present 
Government has taken steps not to repeat other nations' mistakes in the name of development. Ecologically sound use of natural resources is stressed, and conservation figures importantly in the national development plan. In practice, it is being promoted for utilitarian reasons; China cannot afford to do otherwise. An economic argument may be the strongest one for conservation in China and economic incentives are being used. The Government takes the position that traditional use of wildlife is a valid argument for its conservation, so commercially important species will play a major role, and wildlife management is oriented strongly towards these species.

Information on distribution and status of wildlife is sketchy and incomplete. A nationwide survey in 1976 used inadequate census techniques and produced only an approximation of relative abundance in rather restricted areas. Few data are available on birds, so we present primarily information on mammals, much of it based on interviews with wildlife professionals from different regions and field observations made in the summer of 1980.

\section{Distribution of Fauna and Flora}

The eastern half of the country is lower than the west and is influenced by oceanic air masses. Forests range from conifer stands in the north-east to tropical rainforest in the extreme south. The higher northern and north-western part of the country is under the influence of continental winds and the rain shadows of mountain ranges; it is an area of steppes and deserts, dominated by the vast Gobi desert. The west and south-west are dominated by the high mountains and plateaux of the Himalayan chain, and habitats vary from tropical forests in the valleys to barren tundra in the uplands. With such great ecological diversity, there is a rich variety of plant and animal life: more than 30,000 species of higher plants, ${ }^{1} 414$ mammal species, 1166 birds, 315 reptiles, 198 amphibians, and approximately 96 freshwater fish. ${ }^{12}$

China has been divided into seven zoogeographic regions: 1 . North-east; 2. North; 3. Mongolia-Xinjiang; 4. Qinghai-Tibet; 5. South-west; 6. Central; and 7. South (the numbers refer to the map).

The North-East Region is bounded by the Greater and Lesser Hinggan Mountains in the north, the Zhangguangcai Mountains and Changbai Shan in the east, and Song-Liao Plain in the west. The Altay Mountain Range, in the northernmost corner of Xinjiang Province, is also included because of similarities between the fauna of these mountains and the Greater Hinggan Mountains. The climate is cold, temperate, and humid, and many forest species are similar to those in northern Europe and North America. Squirrel Sciurus, stoat Mustela ermina, roe deer Capreolus thibetanus, grouse Tetrao parvirostris, pheasants and waterfowl are common game animals; endangered species such as Siberian tiger Panthera tigris altaica, sika deer Cervus nippon, and red-crowned crane Grus japonensis also inhabit this region. Farming of musk deer Moschus moschiferus, red deer Cervus elaphus, mink Mustela lutreola and stoat is important.

The North China Region, bordered by the Qin Mountains and Huaihe River in the south, the Xiqing Mountain in the west, and the Yellow and Bohai Seas in the east, has a warm, temperate, and relatively dry climate. Much of the land is cultivated, few forests remain, and wildlife is scarce. Animals such as the common macaque Macaca mulatta are found only in remote areas. The browneared pheasant Crossoptilon mantchuricun is endemic. Common game animals include roe deer, hare, and pheasant. 


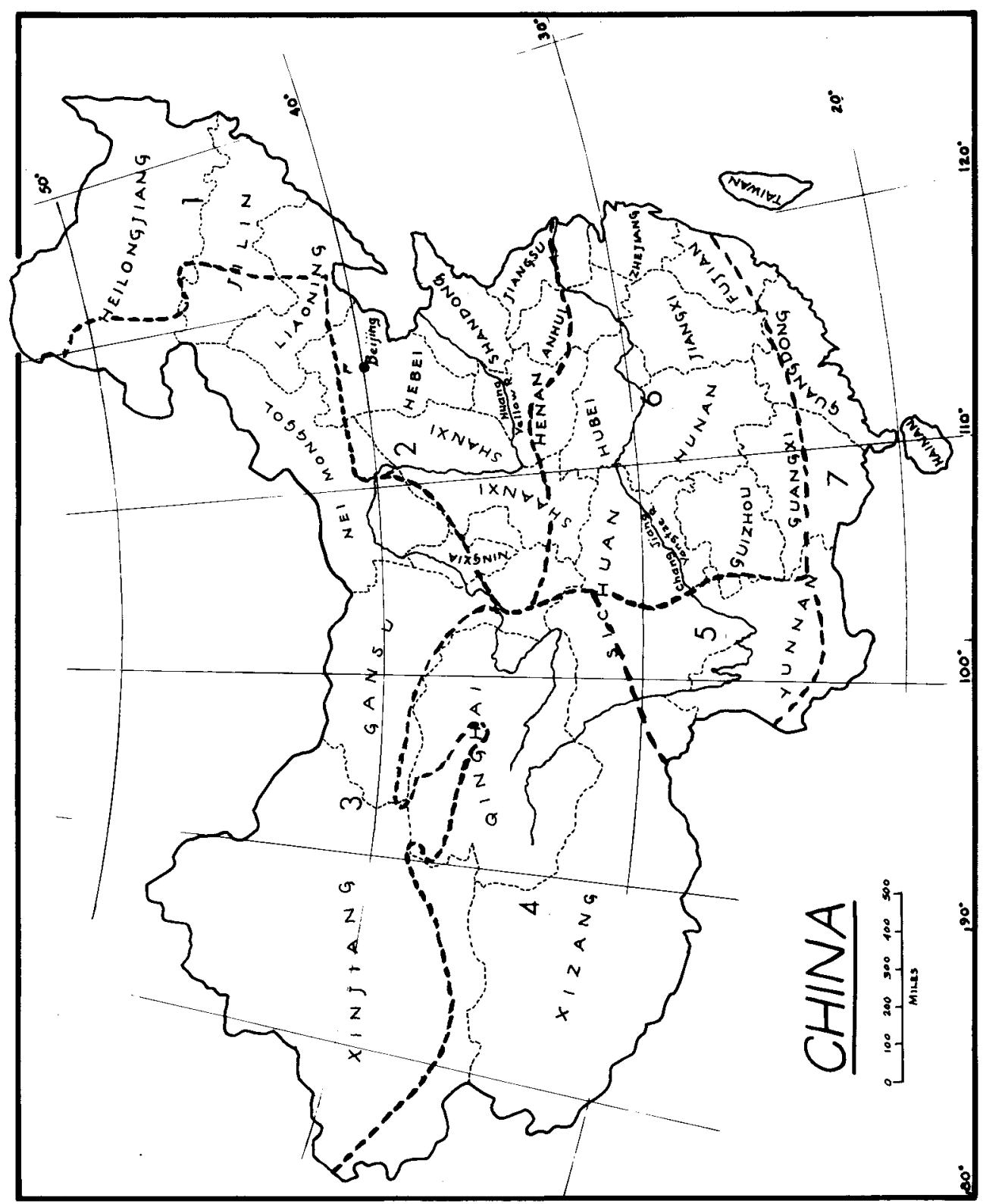


The Mongolia-Xinjiang Region, an area of steppes and deserts, comprises Nei Monggol, the Ordoo Plateau, Alashan, Tarim Basin, Qaidam Basin, Junggar Basin and Tianshan Mountain Range. Ungulates and birds include Bactrian camel Camelus bactrianus, wild horse Equus przewalskii, wild ass $E$. hemionus, gazelle Gazella, great bustard Otis tarda, sand grouse Syrrhaptes paradoxus, and Mongolian lark Melanocorypha mongolica.

The Qinghai-Tibet Region in the west comprises the provinces of Qinghai, Xizang (Tibet), and north-west Sichuan; where the climate is cold and dry, and average elevation $4500 \mathrm{~m}$. Yak Bos grunniens, Tibetan antelope Pantholops hodgsoni, Tibetan wild ass Equus hemionus kiang, snow pigeon Columba leuconota, and several snow finches Montifringilla spp. occur, and the abundant lakes and marshes provide breeding grounds for waterfowl.

The South-west Region includes areas south of Qinghai and Gansu Provinces, south-west Sichuan, the northern half of Yunnan Province, the Hengduan Mountains and the south slope of the Himalayan Mountains. In the high mountains and deep valleys, the alpine steppes harbour blue sheep Pseudois nayaur and marmots Marmota, and the valleys of tropical and subtropical vegetation shelter macaque and elephant Elephas maximus. Giant panda Ailuropoda melanoleuca and takin Budorcas taxicolor, both relict species, occur in the Hengduan Mountains.

The Central Region, in the south-east, includes areas extending from the Qinling Mountains in the north to the upper valley of Xijiang River in the south, and the middle and lower valleys of the Yangtze River. Stoat, raccoon dog Nyctereutes procyonoides, red fox Vulpes vulpes, badger Meles meles, lesser oriental civet Viverricula indica, and pheasant inhabit the region; cranes and mandarin duck Aix galericulata winter here.

The South Region encompasses southern Yunnan Province, Guangdong and Guangxi Provinces, south-east Fujian, Taiwan, Hainan and other islands in the South China Sea. The north is subtropical and the south tropical, and the region, especially Yunnan, contains an extraordinary variety of wildlife. Muntjac Muntiac muntjak is an important game animal, and civet, bamboo pheasant Bambusicola thoracica, and small furbearers ae sought after by hunters.

\section{Present Status}

China covers some seven per cent of the Earth's surface, an area slightly larger than the United States, but less than a quarter of the land is arable. Most of the country is either hilly, mountainous, arid to semi-arid, or situated on high plateaux. A major portion of the fertile land is in the east, around the Yellow and Yangtze River basins, and an estimated 95 per cent of the population is concentrated in the eastern half of the country. It is here that wildlife has suffered the greatest losses. Centuries of human activities in agriculture, timber harvesting, and hunting have reduced wildlife to near extinction. What remains is hidden in inaccessible natural sanctuaries, some of which have been designated as nature reserves.

The largest wildlife populations are in the north-east forested region, where climatic extremes limit human activities. In the summer of 1980 we saw tracks, spoor, and other evidence of red deer, roe deer, musk deer, black bear, wild boar, and badger in the forest stands of northern Heilongjiang Province. The forests were alive with birds, and small mammals such as moles and shrews were seen or heard on the forest floor. But reindeer Rangifer tarandus that once ranged into these forests are now extinct in the wild; they survive only in domesticated herds tended by the Orogen, one of China's many ethnic minorities. 
The greatest wildlife diversity is in the south-west, because the high rugged mountains provide a variety of habitats and limit access by man. We did not visit this region, but game officers who live there talked of problems with poaching and human encroachment. Nonetheless, we suspect that many habitats are in near pristine condition in this part of China.

Few biologists, even those in China, have had an opportunity to visit the north-west desert region. Professor Lee Bo (pers. comm.) who in 1977 travelled the length of Inner Mongolia and into the Bogda Shan Mountains of northern Xinjiang Province, reported that wildlife was greatly reduced because of human encroachment throughout this area. But Bactrian camels still inhabit the valleys along the northern perimeter of the great Taklimakau Desert, and wolves and leopards apparently survive at high elevations in the Tian Mountains, for Gore and Dale report that herdsmen carry rifles to protect their livestock from those two predators. ${ }^{5}$

\section{Values and Uses}

The single most important factor hampering wildlife conservation in China is the traditional use of wild animals for medicinal purposes, meat and skins. China's cultural heritage values wildlife, as is evident in its art and architecture, but the people have always adopted a utilitarian attitude. Several deer species supply important medicinal and industrial products. Antlers are harvested and sold throughout South-east Asia for aphrodisiacs, and deer farmers have discovered that the rejuvenating velvet antlers can be cropped twice a year. Wild red deer of both sexes are harvested in June in Heilongiiang Province, when antlers of males are most valuable and foetuses are near term and provide various medicines for treatment of reproductive maladies in women. Musk from musk deer is used as a base for expensive perfumes in Europe, and for an astonishing diversity of medicinal applications - sore throats, rheumatism, chills and fever plus a variety of ills in domestic livestock.

Tigers, symbols of strength and courage in Chinese culture, are highly valued for the rejuvenating properties of their bones and blood $; 8$ the knee bones are believed to cure rheumatism and arthritis, as are leopard bones. Both are prized for their beautiful pelts as are other cats, and a substantial trade has developed. Gall bladders of the Asiatic black bear are used to treat eye disorders, and their foot pads, like buffalo tongues in early-day North America, are considered a delicacy. Other wild meats, such as monkey, are also regarded as culinary delights in many parts of China. At least 56 bird species have been identified as having high economic value. ${ }^{2}$

Contrary to popular belief, the Chinese historically have not been benevolent toward wildlife. It is often said that Oriental cultures regard wildlife as an integral part of nature to be respected and allowed to live in harmony with man. On the contrary, we noticed that Chinese attitudes differed little from those of Westerners. Certain species have always been regarded as nuisances because they destroy crops, prey on domestic livestock or attack people; in the past, they were even viewed as forces of evil and darkness. Indeed, the savage tribes beyond China's borders were labelled bird people, snake people, or worse, ${ }^{8}$ and the wolf of European folk stories is the same savage beast in China. We noticed that this attitude has not completely disappeared even among those managing the country's wildlife.

Persecution of wild animals regarded as harmful is common. Not long ago, 
sparrows were nearly eliminated when they were named as one of the pests in an official extermination campaign along with mice, flies, and mosquitoes. People killed sparrows diligently and mercilessly, and possibly all sparrow-sized birds in both urban and rural areas became targets. Today birds are scarce wherever people live; this may be partly due to pesticides, which are reportedly used in heavy doses. Thus it is heartening to spot bird communities in remote forested regions and to see nests in the forests.

Carnivore populations likewise have suffered heavy losses. Leopards are shot, trapped, and poisoned around deer farms. Black bears and wild boar are feared by people in the forested areas of the north-east; workers in the forests carry shotguns and shoot bears on sight. Signs of both bear and boar are indeed common in some areas, but the actual danger seems more imagined than real. Knowledgeable woodsmen claim that boars are more dangerous than bears, which are more common, and tigers less dangerous than either.

Rare and endemic species and those economically valuable are protected and the government is encouraging wildlife farming. Red and sika deer are coralled and bred in deer yards, especially in Jilin and Heilongiiang Provinces, to ensure a supply of antlers in velvet; musk deer farms, where musk is extracted without harming or killing the deer, provide extra income to the collectives and reduce the pressure on wild populations. In Shaanxi Province natural areas have been set aside for propagating roe deer, and local hunters are hired to harvest over 10,000 deer each year; the meat is exported to West Germany. Thus domestication and captive breeding of wild animals helps in the conflict between increasing demand for animal products and the dwindling supply of animal resources. The farms provide economic incentives and help to preserve gene pools, two of the main underlying motives of wildlife conservation in China.

The Chinese see other values too in their rare and endemic species. Not only are pandas and tigers, for example, part of their cultural heritage, they are also an attraction for tourists. Natural areas and their wildlife are being assessed now for their potential to attract foreign visitors. The participation of WWF in giant panda research and the proposal for a panda research centre are evidence that rare and endemic species can attract foreign currency to the country. In this case, economic incentives have reinforced the protection of the panda; although the fate of species not obviously valuable to man is less certain. However, China recognizes that economic gain is not the only rationale for conservation, and promotes conservation through the mass media. The outcry that followed the killing of a swan in a Beijing park shows a growing public awareness.

\section{Shortage of Scientists}

Wildlife conservation demands management, but there are several obstacles to this in China. A major one is the lack of scientific data and of trained experts in wildlife ecology and management. However, in one respect, in the rational use of wildlife resources, China is already far ahead of other countries. The technology for domesticating wild animals is well established; with help from the local forestry department, a commune can set up an animal farm with little difficulty, and the market infrastructure, both domestic and international, already exists for various animal products. Preservation of a gene pool in the wild, however, requires more data on population dynamics and natural history of the species. The survival of those rare and endemic species will depend largely on the wise management of their habitats; the establishment of parks and 
reserves for their protection calls for information on territory size, migration patterns, and so on.

China has so far set aside 72 protected areas, ranging from 15 hectares (Nanjiang Hexi Dadoushan Forest Reserve in Fujian) to 480,000ha (Hanma-Hujin Daxinganlin Nature Reserve in Heilongiang); ${ }^{9}$ they cover 0.17 per cent of the land, and it is planned to increase them to 300 covering one per cent of the land. ${ }^{1}$ The need for biological data will then be even more urgent. Wildlife biologists to conduct research will have to be trained, and more managers will be needed. The Cultural Revolution halted basic scientific research, thus contributing to the existing critical shortage of scientists in China, and at present, there are only two wildlife departments in the country. The department in Kunming, in Yunnan Province, was only established in the autumn of 1980 and is not yet in operation, and only 30 wildlife biologists graduate each year from the department in Harbin, Heilongiang Province, not nearly enough to meet the increasing demands for managers, biologists, administrators and teachers.

\section{Poaching}

The disregard people show for protected areas and species is another conservation problem. Several hundred thousand people hunt, and commercial hunting is widespread. ${ }^{4}$ Teams of hunters from collectives shoot to supplement their diet and income, and some ethnic minorities hunt for a living; sport and recreation hunting are increasing. Wildlife has always been a resource for the people to exploit and enjoy, and the establishment of protected areas simply changed some hunters into poachers. Poaching occurs regularly in Changbaishan Nature Reserve, for example, and the local people are quite candid about it; the local government endorses the practice by ignoring it. In areas far from the central government poaching is widely tolerated and the wildlife workers we talked with regarded it as a major problem. China will have to find ways to sell conservation to the local people if it hopes to conserve its dwindling wildlife, and perhaps the economic argument will be the most persuasive one in changing traditional practices and attitudes.

\section{Conflicts of Interest}

Conflicts of interest can undermine the conservation effort, and direct conflicts are evident between the Forestry and Foreign Trade ministries. Wildlife conservation falls under Forestry, trade in animals and animal products under Foreign Trade, which sets specific quotas. A classic example is the trade in endangered cat skins. All felids have some kind of protected status, but the Ministry of Trade maintains quotas for pelts. This essentially creates a legitimate market, and encourages hunters to hunt these endangered cats. Similarly the existence of a market for animal products encourages trade. China has tried to resolve this conflict and enforce protection by establishing a wildlife policy; species are listed in three categories of endangerment and protection laws and penalties explicitly set out. Even a section on non-game species is included.

Conflicts of interest have also arisen among researchers and zoo keepers. Most zoo directors and scientists are advocates of wildlife conservation, but because rare and endemic species are major attractions, many zoos pay high prices for them. Scientists are equally avaricious, and collecting for research has inadvertently contributed to the demise of some rare and endangered species. Both parties have expanded the market for endangered wildlife. 


\section{Summary}

The Chinese regard conservation as important, more for economic than for aesthetic or moral reasons. An economic rationale is a persuasive tool in a developing country such as China. The trade in wild-animal products plus the potential of rare and endemic wildlife species to attract much-needed foreign exchange are important factors. Rational use of wildlife through domestication and sustained-yield harvesting can alleviate pressures on wild populations and help to ensure genetic diversity for the future. Rare and endemic species such as the giant panda attract foreign exchange through tourism and research, and conservation measures preserve a cultural heritage, something of increasing importance to the Chinese.

Several questions arise, however. How do economically unimportant species fit into this scheme? How can conflicts of interest created by economic incentives be resolved? Will the shortage of trained manpower undermine the conservation effort? Once these obstacles are resolved, China may become a leader in wildlife conservation among the developing countries of the world, and show that conservation and development can co-exist.

\section{Acknowledgments}

We would like to thank Professor Lee Bo for his assistance in providing us with current information on the status of wildlife in north-west China. Most of all, we are grateful to the North-east Forest College and the Ministry of Forestry in China for giving us the opportunity to meet and talk with Chinese wildlife professionals.

\section{References}

1. ANONYMOUS. 1980. 300 Natural Reserves. Beijing Review 23, 41: 5-6.

2. CHENG, TSO-HASIN (ed.). 1964. China's Economic Fauna: Birds. US Department of Commerce, Office of Technical Services, Washington, DC 16: 696pp.

3. Foreign Broadcast Information Service. 1979. Forestry Act Adopted by NPC on 23 February 1979. FBIS (3/2/79). No. 43: E1-E9.

4. GREER, C. and R. DOUGHTY. 1979. Wildlife utilization in China. Environmental Conservation 3, 3:200-8.

5. GORE, R. and B. DALE. 1980. Journey to China's Far West. National Geographic 157, 3: 292-331.

6. MYERS, N. 1975. Wildlife in China. International Wildlife 4, 4: 4-10.

7. QU GE-PING. 1980. Protecting the environment: China's environmental protection law (extracts). China Reconstruct. 29, 2: 28-31.

8. SHAFER, E. 1968. Hunting parks and animal enclosures in Ancient China. Journal of Economic and Social History of the Orient 2: 318-43.

9. WANG, HUEN-PU. 1980. Nature conservation in China: The present situation. Parks 5, 1: 1-10.

10. WESTOBY, J. 1975, Forestry in China. Unasylva 2: 20-8.

11. YU, YOU-HAI. 1980. US\$1000 by the year 2000. Beijing Review 23, 43; 16-18.

12. ZHANG, YONG-ZHU. 1979. Zoogeography. In Physical Geography of China. Chinese Academy of Science, ed. Chinese Science Press, Beijing, China. $121 \mathrm{pp}$.

Susan Shen, Yale School of Forestry and Environmental Studies, New Haven, CT 06511, USA.

Dr Ernest D. Ables, College of Forestry, Wildlife and Range Science, University of Idaho, Moscow, ID 82843, USA.

Professor Xiao Qian-zhu, Department of Wildlife, NE Forestry College, Harbin, China. 